\title{
CANDIDÍASE VULVOVAGINAL RECORRENTE: O PAPEL DO ENFERMEIRO
}

\author{
RECURRENT VULVOVAGINAL CANDIDIASIS: THE ROLE OF NURSES
}

\author{
Crislene da Silva Santos ${ }^{1}$ \\ Irailde Neves Bispo ${ }^{2}$ \\ Otaciana Almeida de Souza ${ }^{3}$
}

\begin{abstract}
RESUMO: A candidíase vulvovaginal é uma doença de elevada prevalência, com recidivas frequentes e caracterizada por quadro clínico exuberante e sintomas intensos. É comum se deparar com mulheres portadoras da infecção em busca de tratamento nas unidades básicas de saúde e a consulta de enfermagem é decisiva no rastreamento da candidíase vulvovaginal. $O$ estudo em questão tem como objetivo central apresentar as manifestações clínicas, e caracterizar os fatores predisponentes que contribuem para o desenvolvimento da candidíase vulvovaginal recorrente. $\mathrm{O}$ presente estudo utilizou como método a revisão da literatura, que constitui uma ferramenta importante permitindo a análise de subsídios na bibliografia de forma ampla e sistemática, além de divulgar dados científicos produzidos por outros autores. Utilizaram-se como critério de inclusão, artigos originais, na linguagem portuguesa, respeitando os limites de publicação de até dez anos, com acesso livre e disponível em texto completo online. $\mathrm{Na}$ apresentação dos resultados, foram encontrados 54 artigos, dos quais foram utilizados ir artigos, que atenderam aos critérios de inclusão previamente estabelecidos. Considera-se que a candidíase vaginal apesar de ser uma patologia comum na população feminina, ainda precisa de maiores intervenções educacionais, em especial pelo profissional enfermeiro para que a mulher tenha o tratamento adequado.
\end{abstract}

Palavras-chave: Candidíase vulvovaginal; Papel do profissional de enfermagem; Saúde da mulher; Fatores de risco; Candidíase.

ABSTRACT: Vulvovaginal candidiasis is a disease of high prevalence, with frequent recurrences and characterized by an exuberant clinical picture and intense symptoms. It is common to encounter women with the infection in search of treatment in basic health units and the nursing consultation is decisive in the screening for vulvovaginal candidiasis. The study in question has as main objective to present the clinical manifestations, and to characterize the predisposing factors that contribute to the development of recurrent vulvovaginal candidiasis. The present study used the literature review as a method, which is an important tool allowing the analysis of subsidies in the bibliography in a broad and systematic way, in addition to disseminating scientific data produced by other authors. Original articles, in Portuguese, were used as inclusion criteria, respecting the publication limits of up to ten years, with free access and available in full text online. In the presentation of the results, 54 articles were found, of which in articles were used, which met the inclusion criteria previously

\footnotetext{
${ }^{1}$ Bacharel em Enfermagem- Centro Universitário Estácio de Sergipe. E-mail: crislene-s@hotmail.com.

2 Bacharel em Enfermagem- Centro Universitário Estácio de Sergipe. E-mail: irailde.nb@hotmail.com.

3 Bacharel em Enfermagem- Centro Universitário Estácio de Sergipe. E-mail: tacianasouzasantana@gmail.com
} 
established. It is considered that vaginal candidiasis, despite being a common pathology in the female population, still needs greater educational interventions, especially by the professional nurse so that the woman has the appropriate treatment.

Keywords: Vulvovaginal candidiasis; Role of the nursing professional; Women's health; Risk factors; Candidiasis.

\section{INTRODUÇÃO}

Dentre as vulvovaginites, a candidíase vulvovaginal (CVV) é a segunda mais frequente. É causada por um único agente, porém o mecanismo de transformação da colonização em infecção é multifatorial. A inacurácia no diagnóstico leva a um número significativo de mulheres rotuladas como portadoras de infecção vaginal de repetição e tratadas contra uma suposta patologia que, na realidade, não estava associada ao agente suspeito (CHRISTÓVÃO et al., 2017).

Os sintomas tendem a piorar no período pré-menstrual, no qual há aumento da acidez vaginal. O prurido é considerado o sintoma mais importante, irritação, ardência, eritema, eventualmente fissuras, disúria externa, dispareunia e secreção vaginal que pode variar de aspecto de talco molhado aderido à parede vaginal, com coloração esverdeada, até aparência fisiológica (MUNIZ et al., 2019).

O odor costuma ser incaracterístico e as paredes vaginais podem se encontrar hiperemiadas. Nenhum desses achados é específico e sempre se deve ter em mente que uma grande quantidade de situações, infecciosas ou não, podem provocar queixas semelhantes. A Candidíase Vulvovaginal é desencadeada por fatores de risco, como gestação em uso de contraceptivos orais, antibióticoterapia, diabetes mellitus, entre outros (DUARTE; FARIS; MARTINS, 2019).

Como descrito na Lei n. $\stackrel{0}{7.498}$ de 25 de julho de 1986 , na qual dispõe sobre a regulamentação do Exercício de Enfermagem, cabe ao profissional realizar a consulta de Enfermagem nas Redes de Atenção Básica. Sendo assim, a Consulta de Enfermagem Ginecológica adotada em Unidade Básicas de saúde (UBS) tem um papel importante no acompanhamento de mulheres portadoras de Candidíase Vulvovaginal para efeito de um diagnóstico precoce e preciso (BOATTO et al., 2016).

Nesse ponto é irrelevante a postura do profissional de enfermagem em sua conduta, sendo assim uma consulta bem elaborada e bem realizada são fatores primordiais no diagnóstico desta patologia e também na eficácia do seu tratamento. Ao realizarmos a consulta de enfermagem podemos identificar um alto índice de vulvovaginites dentro delas a candidíase vulvovaginal (HOYER; COTA, 2016). 
É comum se deparar com mulheres portadoras da infecção em busca de tratamento nas unidades básicas de saúde e a consulta de enfermagem é decisiva no seu rastreamento da CVV. Fazse necessário uma observação detalhada sobre os mecanismos de infecção deste microrganismo, pois frente ao diagnóstico correto ou não, essas mulheres ingressam em um tratamento antifúngico, e em algumas situações, este é utilizado desnecessariamente (BOATTO et al., 2016).

Embora seja percebida como um notável agravo à saúde, que acomete majoritariamente as mulheres, sendo desencadeadas por fatores genéticos, ambientais e/ou comportamentais, deve-se levar em conta não somente a suceptibilidade do hospedeiro, mas fazer uma avaliação criteriosa, identificando detalhadamente a possibilidade de outras infecções, um desafio para o profissional enfermeiro que atua na promoção, prevenção e rastreamento por meio da realização do exame citopatológico (VASCONCELOS et al., 2016).

A abrangida prevalência da candidíase vulvovaginal recorrente encontrada na prática diária da atenção básica, consultórios e clínicas de ginecologia, bem como o exacerbado grau de incômodo imposto às pacientes, justificam a identificação dos fatores predisponentes para tal infecção recorrente, além do posicionamento do enfermeiro como protagonista na identificação da infecção e da busca de medidas terapêuticas. Tendo em vista as altas taxas de recidiva da doença, frente aos tratamentos atualmente disponíveis, visa-se estudar as medidas tratativas eficazes e de fácil acesso à população em geral.

O estudo em questão tem como objetivo central apresentar as manifestações clínicas, e caracterizar os fatores predisponentes que contribuem para o desenvolvimento da candidíase vulvovaginal recorrente e evidenciar o papel do enfermeiro na abordagem clínica da candidíase vulvovaginal recorrentes.

\section{METODOLOGIA}

O presente estudo utilizou como método a revisão da literatura, que constitui uma ferramenta importante permitindo a análise de subsídios na literatura de forma ampla e sistemática, além de divulgar dados científicos produzidos por outros autores. Destaca-se pela exigência dos mesmos padrões de rigor, clareza e replicação utilizados em estudos primários, além de compor a mais ampla abordagem metodológica referente às revisões de literatura (CERQUEIRA et al., 2018).

Para a elaboração da revisão as seguintes etapas foram percorridas: escolha do tema; estabelecimento de critérios para inclusão; busca na literatura; definição das informações relevantes a serem extraídas dos estudos selecionados; avaliação dos estudos incluídos seguida de uma 
composição resumida; interpretação dos resultados através de tabela; apresentação da discussão através do ponto de vista.

Utilizaram-se como critério de inclusão, artigos originais, na linguagem portuguesa, respeitando os limites de publicação de até dez anos, com acesso livre e disponível em texto completo online, foram excluídos artigos de revisão de literatura, fora do recorte temporal, artigos de língua estrangeira e fora da temática em questão.

A coleta dos dados foi iniciada em agosto de 2019 e foi realizada por meio das bases de dados, LILACS (Literatura Latino-Americana e do Caribe em Ciências da Saúde), SciELO (Scientific Eletronic Library Online) e BDENF (Banco de Dados em Enfermagem). Através da utilização das terminologias em saúde: candidíase vulvovaginal, papel do profissional de enfermagem, fatores de risco, saúde da mulher e recidiva, consultadas nos descritores em saúde (DeCS), com o auxílio do operador boleano and, que foi utilizado para facilitar e delimitar a busca sempre que necessário.

Foi realizada uma leitura exploratória e seletiva dos títulos e resumos dos artigos para determinar as informações relacionadas ao tema, e a partir dessa seleção, foram excluídas as pesquisas sem relevância ao tema do estudo. Posteriormente fez-se uma leitura analítica, com finalidade de agrupar as informações contidas nos artigos, a fim de responder os objetivos do estudo.

O instrumento de coleta de dados foi composto pelas variantes: título, ano de publicação, objetivo e resultados, por meio de quadro sintético. $\mathrm{Na}$ apresentação dos resultados, as informações de cada estudo, que se apresentaram com mais relevância à revisão, foram exibidas de modo descritivo. Organizados por meio de tabela, sucinta e individualmente para facilitar a análise crítica da amostra, foram utilizados ainda gráficos em barras para facilitar o entendimento dos resultados.

Por se tratar de uma pesquisa bibliográfica, os dados obtidos por meio dessa, seguiram princípios éticos propostos na lei dos direitos autorais $12.853 / \mathrm{I3}$, que dispõe em seu Art. I ${ }^{\circ}$. Essa Lei regula os direitos autorais, entendendo-se sob esta denominação os direitos de autor e os que lhes são conexos.

\section{RESULTADOS}

$\mathrm{Na}$ presente revisão integrativa foram encontrados 54 artigos, dos quais foram utilizados II artigos que atenderam aos critérios de inclusão previamente estabelecidos. Conforme (quadro I) a seguir, obteve-se um panorama dos artigos avaliados nas respectivas bases de dados.

Para tanto, foi elaborado um instrumento de coleta de dados (quadro 2), composto pelas seguintes variantes: tema, autor/ano de publicação, objetivo e resultados. 
QUADRO r: Processo de seleção dos artigos após leitura integral do estudo. Aracaju/SE, 2020.

\begin{tabular}{|l|c|c|c|}
\hline $\begin{array}{c}\text { CRUZAMENTO DOS } \\
\text { OPERADORES BOLEANOS E } \\
\text { DESCRITORES }\end{array}$ & $\begin{array}{c}\text { BASE DE } \\
\text { DADOS }\end{array}$ & $\begin{array}{c}\text { ARTIGOS } \\
\text { ENCONTRADOS }\end{array}$ & $\begin{array}{c}\text { ARTIGOS } \\
\text { SELECIONADOS }\end{array}$ \\
\hline $\begin{array}{l}\text { Candidíase vulvovaginal and } \\
\text { Recidiva }\end{array}$ & LILACS & 20 & 3 \\
\hline $\begin{array}{l}\text { Papel do profissional de enfermagem } \\
\text { and Saúde da mulher }\end{array}$ & LILACS & Io & 4 \\
\hline Candidíase and Fatores de risco & SCIELO & 2 I & 2 \\
\hline Candidíase and Recidiva & BDENF & 3 & II \\
\hline Total & - & 54 & 2 \\
\hline
\end{tabular}

Fonte: Elaborado pelas autoras.

Pôde-se constatar que a Literatura Latino-Americana e do Caribe em Ciências da Saúde (LILACS) foi a base de dados com maior número de artigos encontrados e utilizados pertinentes ao tema proposto para a presente revisão, conforme gráfico I.

Gráfico I - Bases de dados utilizados para extração dos artigos selecionados. Aracaju/SE, 2020.

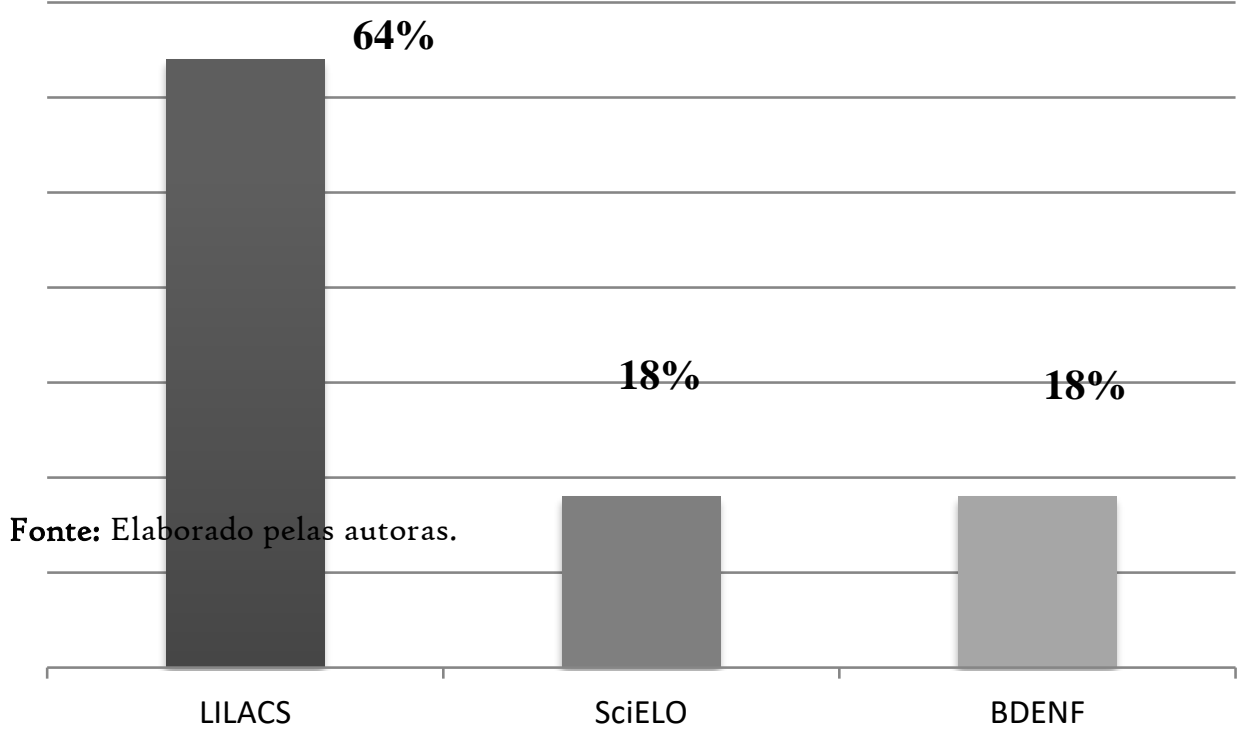


Fluxograma I - Processo de identificação, seleção, inclusão e exclusão dos estudos. Aracaju/SE, 2019 .

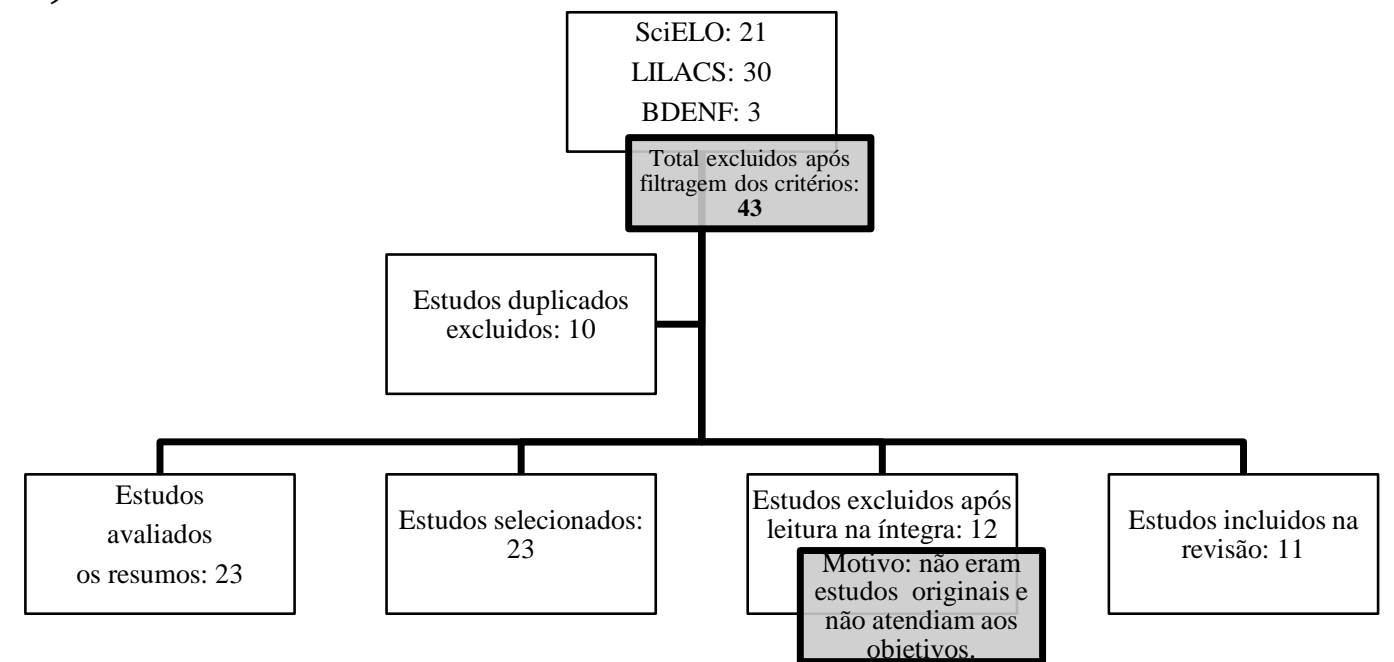

Fonte: Elaborado pelas autoras.

O processo de identificação, seleção, inclusão e exclusão dos estudos se deram nas seguintes etapas: inicialmente foi realizada a retirada dos artigos duplicados, procedeu-se à leitura dos títulos e resumos, à luz dos critérios de inclusão, sendo excluídos nessa etapa os que não atenderam aos critérios e objetivos do estudo.

Quadro 2- Apresentação da síntese de artigos incluídos na revisão integrativa. Aracaju/SE, 2020.

\begin{tabular}{|c|c|c|c|}
\hline $\begin{array}{l}\text { TÍTULO DO } \\
\text { ARTIGO }\end{array}$ & AUTORES/ANO & OBJETIVOS & $\begin{array}{l}\text { MANIFESTAÇÕES } \\
\text { CLÍNICAS DA } \\
\text { CANDIDÍASE } \\
\text { VULVOVAGINAL }\end{array}$ \\
\hline $\begin{array}{l}\text { Espécies de candida } \\
\text { predominantes em } \\
\text { secreção vaginal de } \\
\text { mulheres sintomáticas } \\
\text { e não. }\end{array}$ & $\begin{array}{l}\text { CHRISTÓVÃO et } \\
\text { al., 2017. }\end{array}$ & $\begin{array}{l}\text { Avaliar as espécies de } \\
\text { candida predominantes } \\
\text { em secreção vaginal em } \\
\text { mulheres sintomáticas } \\
\text { e assintomáticas. }\end{array}$ & $\begin{array}{l}\text { No estudo realizado com } \\
\text { mulheres usuárias de uma UBS, } \\
\text { as manifestações mais comuns e } \\
\text { recorrentes foram: prurido } \\
\text { vulvovaginal, ardor ou disúria, } \\
\text { corrimento branco, grumoso, } \\
\text { inodoro e com aspecto caseoso. }\end{array}$ \\
\hline $\begin{array}{l}\text { Métodos diagnósticos } \\
\text { para a caracterização } \\
\text { de candidíase e } \\
\text { papilomavírus } \\
\text { humano. }\end{array}$ & $\begin{array}{l}\text { DUARTE; } \\
\text { FARIA; } \\
\text { MARTINS, } 2019 .\end{array}$ & $\begin{array}{l}\text { Oferecer a classe } \\
\text { feminina } \\
\text { esclarecimento a cerca } \\
\text { da } \\
\text { atividade microbiana } \\
\text { residente e patológica a } \\
\text { compor a microbiota } \\
\text { vaginal. }\end{array}$ & $\begin{array}{l}\text { Das mulheres estudadas, 50\% } \\
\text { apresentaram episódios } \\
\text { recorrentes durante o ano, com } \\
\text { os mesmos sintomas, nos quais } \\
\text { foram pruridos intensos e } \\
\text { corrimento branco grumoso. }\end{array}$ \\
\hline
\end{tabular}




\begin{tabular}{|c|c|c|c|}
\hline $\begin{array}{l}\text { Vinhetas da família de } \\
\text { sequência semelhante } \\
\text { à aglutinina (Als) de } \\
\text { Candida albicans: uma } \\
\text { revisão da estrutura e } \\
\text { função das proteínas } \\
\text { Als. }\end{array}$ & $\begin{array}{l}\text { HOYER; COTA, } \\
2016\end{array}$ & $\begin{array}{l}\text { Definir a transição do } \\
\text { fungo de comensal para } \\
\text { patogênico, fatores de } \\
\text { virulência expressos } \\
\text { por C. albicans. }\end{array}$ & $\begin{array}{l}\text { A candidíase se manifesta } \\
\text { quando fatores predisponentes, } \\
\text { fisiológicos, patológicos e } \\
\text { mecânicos, modificam o } \\
\text { relacionamento que ocorre } \\
\text { entre o hospedeiro e a } \\
\text { microbiota natural. }\end{array}$ \\
\hline $\begin{array}{l}\text { Prevalência } \\
\text { papilomavírus } \\
\text { humano anal tipo- } \\
\text { específico } \\
\text { homens, de acordo } \\
\text { com a preferência } \\
\text { sexual e o status de } \\
\text { HIV. }\end{array}$ & $\begin{array}{l}\text { MARRA; LIN; } \\
\text { CLINFFORD, } \\
\text { 20I8. }\end{array}$ & $\begin{array}{l}\text { Verificar a prevalência } \\
\text { de HPV anal, bucal e } \\
\text { genital em ambulatório } \\
\text { público de } \\
\text { Coloproctologia, com } \\
\text { base no exame de } \\
\text { captura híbrida. }\end{array}$ & $\begin{array}{l}\text { Mais da metade das pacientes } \\
\text { estudadas apresentaram prurido } \\
\text { intenso como queixa principal. }\end{array}$ \\
\hline $\begin{array}{l}\text { Prevalência } \\
\text { candidíase } \\
\text { vulvovaginal em } \\
\text { mulher de i8 a } 30 \text { anos. }\end{array}$ & MUNIZ, 2019. & $\begin{array}{l}\text { Investigar a } \\
\text { prevalência de infecção } \\
\text { por espécies do gênero } \\
\text { Candida em mulheres } \\
\text { com sintomas e sinais } \\
\text { clínicos de } \\
\text { vulvovaginites a } \\
\text { encaminhar a } \\
\text { positivas para o } \\
\text { tratamento específico. }\end{array}$ & $\begin{array}{l}\text { A candidíase generalizada é } \\
\text { uma infecção invasiva a partir } \\
\text { de uma lesão primária. O fungo } \\
\text { pode originar focos } \\
\text { metastáticos. }\end{array}$ \\
\hline $\begin{array}{l}\text { Prevalência do DNA } \\
\text { do papilomavírus } \\
\text { humano e do câncer } \\
\text { peniano e na neoplasia } \\
\text { intraepitelial peniana. }\end{array}$ & OLESEN, 2019. & $\begin{array}{l}\text { Determinar a } \\
\text { prevalência de } \\
\text { coilocitose em biópsias } \\
\text { penianas de parceiros } \\
\text { de mulheres com lesões } \\
\text { genitais induzidas pelo } \\
\text { HPV e analisar os } \\
\text { fatores de risco } \\
\text { envolvidos com a } \\
\text { infecção peniana. }\end{array}$ & $\begin{array}{l}56 \quad \text { pacientes } \quad(70 \%) \\
\text { apresentaram lesões } \\
\text { acetobrancas e azul de toluidina } \\
\text { positivas. Apresentando } \\
\text { corrimento branco grumoso e } \\
\text { aspecto caseoso. }\end{array}$ \\
\hline $\begin{array}{l}\text { TÍTULO DO } \\
\text { ARTIGO }\end{array}$ & AUTORES/ANO & OBJETIVOS & $\begin{array}{c}\text { O PAPEL DO ENFERMEIRO } \\
\text { NA ABORDAGEM } \\
\text { CLÍNICA DA CVV } \\
\end{array}$ \\
\hline $\begin{array}{l}\text { O papel dos parceiros } \\
\text { sexuais sintomáticos e } \\
\text { assintomáticos nas } \\
\text { vulvovaginites } \\
\text { recorrentes. }\end{array}$ & $\begin{array}{l}\text { BOATTO et al., } \\
\text { 20I5. }\end{array}$ & $\begin{array}{l}\text { Identificar as espécies } \\
\text { predominantes e o } \\
\text { papel dos parceiros } \\
\text { sexuais na manutenção } \\
\text { das vulvovaginites } \\
\text { recorrentes por } \\
\text { Candida spp. }\end{array}$ & $\begin{array}{l}\text { A consulta de enfermagem é de } \\
\text { suma importância no } \\
\text { diagnóstico da CVV, em } \\
\text { virtude da abordagem } \\
\text { sindrômica associando os sinais } \\
\text { e relatos da paciente além do } \\
\text { exame citopatológico. }\end{array}$ \\
\hline $\begin{array}{l}\text { Microbiota vaginal de } \\
\text { vaginose bacteriana } \\
\text { assintomática } \\
\text { candidíase } \\
\text { vulvovaginal: são } \\
\text { diferentes da } \\
\text { microbiota normal. }\end{array}$ & $\begin{array}{l}\text { PRAMANICK, } \\
\text { 2019. }\end{array}$ & $\begin{array}{l}\text { Apresentar os novos } \\
\text { conhecimentos sobre o } \\
\text { ecossistema vaginal, } \\
\text { enfatizando os métodos } \\
\text { não cultiváveis de } \\
\text { identificação } \\
\text { microbiana. }\end{array}$ & $\begin{array}{l}\text { As sequências de eventos que } \\
\text { culminam com } \\
\text { desenvolvimento da vaginose } \\
\text { bacteriana, } \\
\text { caracterizada por profunda } \\
\text { alteração na flora vaginal }\end{array}$ \\
\hline
\end{tabular}




\begin{tabular}{|c|c|c|c|}
\hline & & & $\begin{array}{l}\text { fisiológica, ainda necessitam ser } \\
\text { determinadas. }\end{array}$ \\
\hline $\begin{array}{l}\text { Estudo comparativo } \\
\text { entre terapia oral e } \\
\text { local no tratamento de } \\
\text { corrimentos vaginais: } \\
\text { candidíase, } \\
\text { tricomoníase e } \\
\text { vaginose bacteriana. }\end{array}$ & $\begin{array}{l}\text { VASCONCELOS, } \\
\text { 2016. }\end{array}$ & $\begin{array}{l}\text { Comparar os } \\
\text { medicamentos } \\
\text { disponíveis atualmente } \\
\text { para o tratamento da } \\
\text { candidíase vaginal, da } \\
\text { tricomoníase, e } \\
\text { vaginose bacteriana. }\end{array}$ & $\begin{array}{l}\text { Além dos corrimentos, a } \\
\text { candidíase pode se manifestar } \\
\text { por hiperemia, edema vulvar, } \\
\text { ardência durante o coito, disúria } \\
\text { e polaciúria. }\end{array}$ \\
\hline \begin{tabular}{lr} 
Disbiose & \multicolumn{2}{c}{ vaginal $e$} \\
risco de papilomavírus \\
humano e & câncer \\
cervical: & revisão \\
sistemática & e \\
metanálise. &
\end{tabular} & $\begin{array}{l}\text { BRUSSELAERS et } \\
\text { al., } 2018 .\end{array}$ & $\begin{array}{l}\text { Analisar a prevalência } \\
\text { de infecção pelo vírus } \\
\text { do papiloma humano } \\
\text { (HPV) em mulheres } \\
\text { no Brasil. }\end{array}$ & $\begin{array}{l}\text { As técnicas de citologia } \\
\text { realizadas pelo profissional } \\
\text { enfermeiro resultam em } \\
\text { diversas classificações e } \\
\text { estimativas de prevalência, } \\
\text { considerando separadamente } \\
\text { cada patologia. }\end{array}$ \\
\hline $\begin{array}{l}\text { Eficácia e segurança } \\
\text { da vacinação contra o } \\
\text { papilomavírus } \\
\text { humano em homens. }\end{array}$ & $\begin{array}{l}\text { HARDER et al., } \\
\text { 2oi } 8 .\end{array}$ & $\begin{array}{l}\text { Apresentar } \\
\text { importância da vacina } \\
\text { como agente de } \\
\text { imunização contra o } \\
\text { papilomavírus humano } \\
\text { (HPV) como } \\
\text { contribuição para } \\
\text { formulação de políticas } \\
\text { públicas na área de } \\
\text { prevenção da doença } \\
\text { em questão. }\end{array}$ & $\begin{array}{l}\text { A visão holística do enfermeiro } \\
\text { frente à abordagem desses } \\
\text { pacientes traz um fechamento } \\
\text { de diagnóstico mais fidedigno e } \\
\text { consequentemente um } \\
\text { tratamento mais eficaz. }\end{array}$ \\
\hline $\begin{array}{l}\text { Microbiota vaginal de } \\
\text { vaginose bacteriana } \\
\text { assintomática } \\
\text { candidíase } \\
\text { vulvovaginal: são } \\
\text { diferentes da } \\
\text { microbiota normal. }\end{array}$ & $\begin{array}{l}\text { PRAMANICK, } \\
\text { 20I9. }\end{array}$ & $\begin{array}{l}\text { Apresentar os novos } \\
\text { conhecimentos sobre o } \\
\text { ecossistema vaginal, } \\
\text { enfatizando os métodos } \\
\text { não cultiváveis de } \\
\text { identificação } \\
\text { microbiana. }\end{array}$ & $\begin{array}{l}\text { As sequências de eventos que } \\
\text { culminam com } \\
\text { desenvolvimento da vaginose } \\
\text { bacteriana, } \\
\text { caracterizada por profunda } \\
\text { alteração na flora vaginal } \\
\text { fisiológica, ainda necessitam ser } \\
\text { determinadas. }\end{array}$ \\
\hline
\end{tabular}

Fonte: Elaborado pelas autoras.

\section{DISCUSSÃO}

Para facilitar o entendimento dos conteúdos abordados, a discussão foi dividida em duas categorias, visando responder aos objetivos propostos, quais sejam: manifestações clínicas e os fatores predisponentes para o desenvolvimento da candidíase vulvovaginal e por fim, o papel do enfermeiro na abordagem clínica da candidíase vulvovaginal recorrente. 


\section{CATEGORIA I: MANIFESTAÇÕES CLÍNICAS E OS FATORES PREDISPONENTES PARA O DESENVOLVIMENTO DA CANDIDÍASE VULVOVAGINAL}

A Candidíase Vulvovaginal Recorrente (CVR), um importante problema ginecológico, presente em até $75 \%$ das mulheres ao longo da vida. É mais comumente causada por Candida Albicans, mas outras espécies como a C. Glabrata, C. Krusei, embora raros, podem estar associados à doença. Estudos indicam que Candida sp. compõe a microbiota vaginal, no entanto, a manifestação da doença relacionada com a multiplicação exacerbada do fungo pode ocorrer por vários fatores, entre eles, a imunossupressão local ou sistêmica (CHRISTÓVÃO et al., 2017).

Os principais sintomas da candidíase são pruridos, dor na vulva, dispareunia, disúria e corrimento esbranquiçado. O desconforto característico associado à venda livre de antifúngicos pode explicar o alto índice de automedicação e CVR (VASCONCELOS et al., 2016).

A espécie de Candida predominante em mulheres com e sem sintomas é a albicans, fato estes que demonstra a alta virulência desta espécie perante as outras. Sendo que um dos fatores de virulência responsáveis pela patogenicidade da Candida albicans é a sua capacidade hemolítica, resultando em maior eficácia no desenvolvimento da infecção (BOATTO et al., 2016).

$\mathrm{O}$ acometimento de mulheres pela infecção em questão sem sintomatologia é um fator importante a ser investigado, principalmente em casos de internação hospitalar quando a doença constitui caráter de risco ao paciente, podendo levar a infecções sistêmicas (DUARTE; FARIS; MARTINS, 2019).

Clinicamente, as CVV se caracterizam por prurido e queimação intensos, dispareunia, disúria, edema, eritema vulvovaginal e pela eliminação de corrimento cremoso e grumoso, de coloração clara, amarelo esbranquiçada (CHRISTÓVÃO et al., 2017).

Os sintomas tendem a piorar no período pré-menstrual, no qual há aumento da acidez vaginal. As lesões podem se estender ao períneo e regiões perianal e inguinal. Nos casos típicos, notam-se pontos amarelo esbranquiçados aderidos às paredes da vagina e colo. O prurido é considerado o sintoma mais importante, quando comparada com outras etiologias (MUNIZ et al., 2019).

A Candidíase vulvovaginal acomete 50 a $75 \%$ das mulheres em alguma fase da vida 1,7, sendo que 50\% apresentam outros episódios e 5\% têm Candidíase Vulvovaginal Recorrente, definida como quatro ou mais episódios em um ano, não relacionados à antibioticoterapia prévia. Dentre as espécies, Candida albicans é responsável por 85 a 90\% dos casos de candidíase vulvovaginal recorrente, seguida pelas espécies C. Glabrata, C. Tropicalis (DUARTE; FARIS; MARTINS, 2019). 
São citados na literatura diversos fatores predisponentes, sendo os mais frequentemente encontrados uso de contraceptivos hormonais orais ou outros medicamentos contendo estrogênios, a gestação, o Diabete Melito, uso prévio de antibióticos, obesidade e o uso de roupas íntimas contendo fibras sintéticas (VASCONCELOS et al., 2016).

Não se compreende por completo o modo como a candida causa as vulvovaginites. Sabe-se que são necessárias as interações de diversos fatores, não bastando apenas à presença do fungo, uma vez que a Candida é comensal comumente encontrado na vagina de mulheres assintomáticas (MUNIZ et al., 2019).

Os mecanismos parecem envolver alterações não somente no meio ambiente vaginal e na microflora vaginal, como também nos mecanismos de defesa do organismo. Os sintomas da CVV ocorrem na vigência de respostas agressivas dos neutrófilos polimorfonucleares e não por falha na defesa induzida pelos Linfócitos T Helper (CD4). Trata-se, portanto, de uma resposta inadequada e exagerada e não de uma falha da imunidade celular. A proteção, por sua vez, parece ser inata e não ligada a processos inflamatórios (DUARTE; FARIS; MARTINS, 2019).

Uma das principais queixas que acarretam a procura de postos de saúdes são os corrimentos vaginais recorrentes, por sua grande maioria sendo causadas por vaginites, porém o primeiro diagnóstico da candidíase vulvovaginal se dá por um exame pélvico (OLESEN, 2019).

\section{CATEGORIA II: O PAPEL DO ENFERMEIRO NA ABORDAGEM CLÍNICA DA CANDIDÍASE VULVOVAGINAL RECORRENTE}

A avaliação da candidíase requer a visualização detalhada da secreção vaginal, da vagina como um todo e do colo do útero, coletando e avaliando a amostra da secreção ao microscópio e observar se de fato se trata de uma infecção apenas por um tipo de microrganismo. A visualização do colo do útero através do Papanicolau é importante para retirar conclusões de outras doenças como o carcinoma devido ao corrimento vaginal anormal (PRAMANICK et al., 2019).

Nesse sentindo, além de exames clínicos, que seja elaborado um reconhecimento histórico da vida da paciente, para determinar meios de prevenir e combater as infecções vulvovaginais. $O$ profissional de saúde precisa ter conhecimento sobre o ciclo menstrual da paciente, seu histórico de relações sexuais, os cuidados com a higiene pessoal, condições sócio econômicas, hereditariedade e fatores correspondentes ao estado patológico da paciente, assim terá uma boa avaliação do estado clínico e melhoria da qualidade de vida dessa mulher (HOYER; COTA, 2016). 
A identificação também pode ser demonstrada através de análises físico-químicas em relação ao corrimento vaginal, tratando-se de um método de baixo custo na utilização de um papel de $\mathrm{pH}$ Whatman, se a vagina produz um $\mathrm{pH}$ menor que quatro e meio pode diferenciar a candidíase de outras doenças como a Vaginose Bacteriana ou tricomoníase que elevam o pH (PRAMANICK et al., 2019).

O diagnóstico da instalação e manifestação do vírus HPV acorre através de um conjunto de dados da história da paciente, exames complementares como forma de apoio para a correlação do vírus com outras infecções na região vaginal e do útero, e atualmente abrangendo a biologia molecular, que em muito contribui para identificação mais precisa da tipagem viral do HPV (OLESEN, 2019).

O exame físico e o Papanicolau é um dos métodos mais difundidos no mundo, por se tratar de uma técnica de baixo custo e fácil de realizar em diversos locais, além de ser um procedimento privativo do enfermeiro na rede de saúde primária. Também uma de suas vantagens é que esse método não é invasivo e agressivo não ocorrendo agressões ao tecido vaginal (HARDER et al., 2018).

De fato, o teste do Papanicolau não caracteriza e identifica o HPV, mas através da técnica é possível observar através de microscópio as alterações celulares acometidas pelo vírus, denominando esse feito de "screening", podendo obter informações sobre as possíveis complicações que acarretam as lesões intraepitelias ou até mesmo um câncer invasor (MARRA; LIN; CLIFFORD, 20I8).

A flora vaginal é outro fator importante. A flora normal é constituída fundamentalmente de bactérias gram positivas, mormente os lactobacilos de diversas espécies, sobretudo os acidófilos, mas pode conter grande variedade de bactérias gram positivas e negativas, aeróbias e anaeróbias, cujo equilíbrio pode ser quebrado por alterações no meio ambiente vaginal induzida por alterações do próprio epitélio da vagina (DUARTE; FARIS; MARTINS, 2019).

O enfermeiro como integrante da equipe de saúde, e responsável pelo cuidado integral, deve estabelecer uma visão holística acerca deste tema, atentando-se para a complexidade desta infecção, os fatores predisponentes envolvidos e sua dificuldade diagnóstica (HARDER et al., 2018).

\section{CONSIDERAÇÕES FINAIS}

Embora a CVV seja percebida como um notável agravo à saúde considera-se que acomete majoritariamente as mulheres, sendo desencadeadas por fatores genéticos, ambientais e/ou comportamentais, deve-se perceber a presença de outros microrganismos que também causam infecções nesse contexto, apresentando sintomas semelhantes, e por isso deve-se levar em conta não 
somente a susceptibilidade do hospedeiro, mas fazer uma avaliação criteriosa, identificando detalhadamente a possibilidade de outras infecções, um desafio para o profissional enfermeiro que atua na promoção, prevenção e rastreamento por meio da realização do exame citopatológico.

Sabe-se que a microbiota residente exerce um importante papel na modulação do sistema imune e redução de riscos conferidos por determinados patógenos. Da mesma forma ocorre com a microbiota vaginal, que se adapta a diversas alterações, porém seu equilíbrio pode ser alterado em virtude da diversidade microbiana e de condições imunológicas ou ambientais.

Com esses resultados podemos concluir que a candidíase vaginal apesar de ser uma patologia comum na população feminina, ainda precisa de maiores intervenções educacionais, em especial pelo profissional enfermeiro para que a mulher tenha o tratamento adequado. O enfermeiro durante a consulta de enfermagem deve reconhecer todas as necessidades da mulher para que sejam atendidas na sua integralidade.

Como dificuldades para elaboração do estudo, pode-se elencar a quantidade reduzida de publicações encontradas sobre a temática, estudos recentes e informações mais consistentes para realização da pesquisa. Entretanto, foi possível atingir aos objetivos propostos, discutindo as temáticas por categorias.

\section{REFERÊNCIAS}

BOATTO, H. F. et al. O papel dos parceiros sexuais sintomáticos e assintomáticos nas vulvovaginites recorrentes. Revista de ginecologia e obstetrícia, v. 37, n. 7, p. 314-318, 2015.

BRUSSELAERS, N. et al. Disbiose vaginal e risco de papilomavírus humano e câncer cervical: revisão sistemática e metanálise. Revista Americana de Obstetrícia e Ginecologia, v. 3, n. 9, 2018.

CHRISTÓVÃO, R. G. et al. Espécies de candida predominantes em secreção vaginal de Mulheres sintomáticas e não. Revista UBRA Torres, v. I, n.I, p. I-13, 2017.

DUARTE, S. M. S.; FARIA F. V.; MARTINS, M. O. Métodos diagnósticos para a caracterização de candidíase e papilomavírus humano. Journal of Development, v.5, n.10, p. 18083-18091, 2019.

HARDER, T. et al. Eficácia, eficácia e segurança da vacinação contra o papilomavírus humano em homens: uma revisão sistemática. BMC medicine, v. ı6, n. I, p. IIo, 2018.

HOYER, L. L.; COTA, E. Vinhetas da família de sequência semelhante à aglutinina (Als) de Candida albicans: uma revisão da estrutura e função das proteínas Als. Revista Fronteiras em microbiologia, v. 7, p. 280, 2016.

MARRA, E.; LIN, C.; CLIFFORD, G. M. Prevalência de papilomavírus humano anal tipoespecífico entre homens, de acordo com a preferência sexual e o status de HIV. O Jornal de doenças infecciosas, v. 219, n. 4, p. 590-598, 2018. 
MUNIZ, S. D. B. Prevalência de candidíase vulvovaginal em mulher de I8 a 30 anos. Journal of biology, v.15, n. I, p. 9-17, 2019.

OLESEN, T. B. C. Prevalência do DNA do papilomavírus humano e do câncer peniano e na neoplasia intraepitelial peniana. The Lancet Oncology, v. 20, n. I, p. 145-158, 2019.

PRAMANICK, R. et al. Microbiota vaginal de vaginose bacteriana assintomática e candidíase vulvovaginal: são diferentes da microbiota normal? Revista Patogênese, v. 4, n. I, p. 103 599, 2019.

VASCONCELOS, C. N. E. et al. Estudo comparativo entre terapia oral e Local no tratamento de corrimentos vaginais: Candidíase, tricomoníase e vaginose Bacteriana. Journal of Surgery, v. $15, n$. I, p. 123-128, 2016. 